\title{
Mitigation of myocardial fibrosis by molecular cardiac surgery-mediated gene overexpression
}

\author{
Michael G. Katz, MD, PhD, ${ }^{a, b}$ Elizabeth Brandon-Warner, $\mathrm{PhD},{ }^{\mathrm{c}}$ Anthony S. Fargnoli, $\mathrm{PhD},{ }^{\mathrm{a}, \mathrm{b}}$ \\ Richard D. Williams, BS, ${ }^{a}$ Andrew P. Kendle, BS, ${ }^{a}$ Roger J. Hajjar, MD, ${ }^{b}$ Laura W. Schrum, PhD, ${ }^{c}$ and \\ Charles R. Bridges, MD, ScD
}

\begin{abstract}
Objective: Heart failure is accompanied by up-regulation of transforming growth factor beta signaling, accumulation of collagen and dysregulation of sarcoplasmic reticulum calcium adenosine triphosphatase cardiac isoform $2 \mathrm{a}$ (SERCA2a). We examined the fibrotic response in small and large myocardial infarct, and the effect of overexpression of the SERCA2a gene.
\end{abstract}

Methods: Ischemic cardiomyopathy was induced via creation of large or small infarct in 26 sheep. Animals were divided into 4 groups: small infarct; large infarct with heart failure; gene-treated (large infarct with heart failure followed by adeno-associated viral vector, serotype 1.SERCA2a gene construct transfer by molecular cardiac surgery with recirculating delivery); and control.

Results: Heart failure was significantly less pronounced in the gene-treated and small-infarct groups than in the large-infarct group. Expression of transforming growth factor beta signaling components was significantly higher in the large-infarct group, compared with the small-infarct and gene-treated groups. Both the angiotensin II type 1 receptor and angiotensin II were significantly elevated in the small- and large-infarct groups, whereas gene treatment diminished this effect. Active fibrosis with de novo collagen synthesis was evident in the large-infarct group; the small-infarct and gene-treated groups showed less fibrosis, with a lower ratio of de novo to mature collagen.

Conclusions: The data presented provide evidence that progression of fibrosis is mediated through increased transforming growth factor beta and angiotensin II signaling, which is mitigated by increased SERCA2a gene expression. (J Thorac Cardiovasc Surg 2016;151:1191-200)

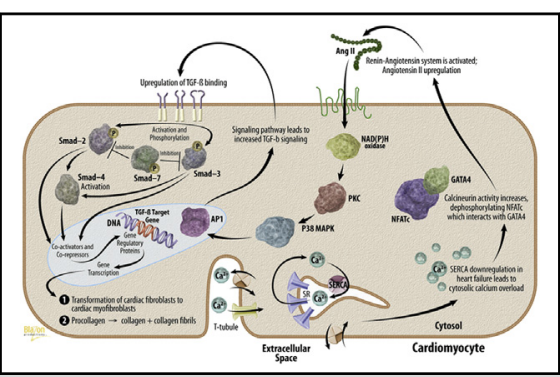

Proposed mechanism due to SERCA2a downregulation through angiotensin $\|$ and TGF- $\beta$ to fibrosis.

\section{Central Message}

Gene therapy by molecular cardiac surgerymediated SERCA2a has a cardioprotective effect, with mitigation of fibrosis.

\section{Perspective}

Molecular cardiac surgery with recirculating delivery would offer a unique solution for the clinic and usher in the concept of targeted transvascular gene delivery. We found that SERCA2a gene delivery restricts the progression of fibrosis in our heart failure model. By combining this delivery method with this therapy, SERCA2a could be safely and effectively delivered after myocardial infarction, to prevent cardiac remodeling.

See Editorial Commentary page 1200.

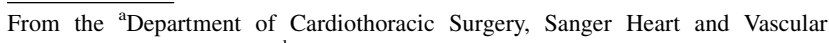
Institute, Charlotte, NC; ${ }^{\mathrm{b}}$ Cardiovascular Research Center, Mount Sinai School of Medicine, New York, NY; and ${ }^{\mathrm{c}}$ Liver Pathobiology Laboratory, Carolinas Medical Center, Charlotte, NC.

This study was supported by National Institutes of Health grant 2-R01 HL083078-08, and grants from the James H. Heineman Foundation.

M.G.K. and E.B.-W. contributed equally to this work.

L.W.S. and C.R.B. are co-senior authors of this article

Received for publication July 14, 2015; revisions received Nov 11, 2015; accepted for publication Nov 19, 2015; available ahead of print Jan 5, 2016.

Address for reprints: Michael G. Katz, MD, PhD, Sanger Heart and Vascular Institute, 1001 Blythe Blvd, Ste 300, Charlotte, NC 28203 (E-mail: crbridges99@ gmail.com ordr.michael.katz@gmail.com).

$0022-5223 / \$ 36.00$

Copyright $(2016$ by The American Association for Thoracic Surgery

http://dx.doi.org/10.1016/j.jtcvs.2015.11.031
}

Supplemental material is available online.

Myocardial infarction (MI) results in extensive left ventricular remodeling in both infarcted and noninfarcted zones, with subsequent development of fibrosis and heart failure. At the molecular level, the remodeling is accompanied by a reparative deposition of extracellular matrix, designed to maintain cardiac structural integrity. Altering this process presents a significant therapeutic opportunity in the management of heart failure. ${ }^{1}$ In contrast to traditional 


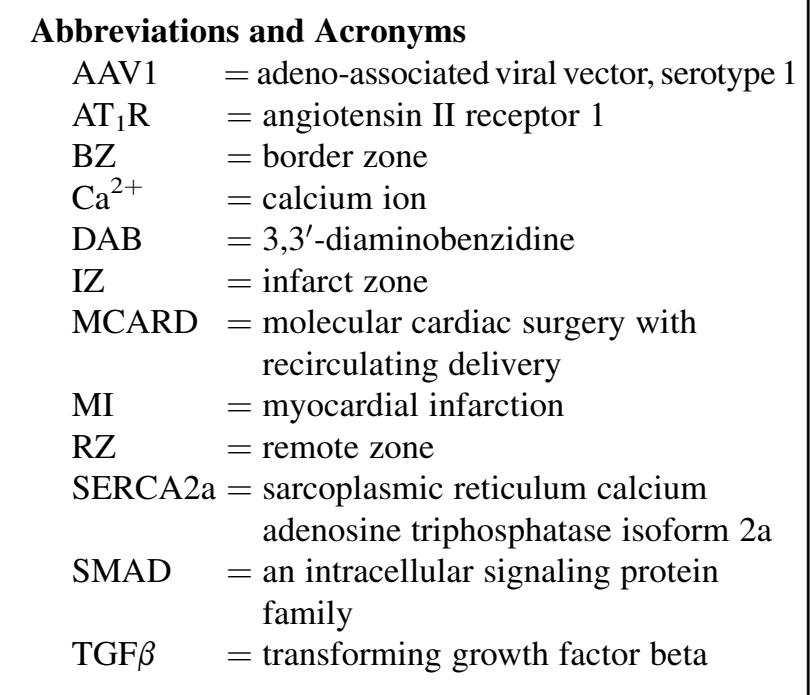

treatments, gene therapy seems promising because it can alter the genetic structure of myocardial cells and the extracellular matrix.

One important contributor to the development of fibrosis is the transforming growth factor beta (TGF $\beta 1$ )-SMAD signaling cascade, which stimulates collagen expression and other downstream profibrotic targets and is markedly up-regulated after MI. ${ }^{2}$ Additionally, it is a potent regulator of the multiple stages of the cell cycle in the heart and is integral to infarct healing, myocardial hypertrophy, and postinfarction remodeling. ${ }^{3}$ The signaling of TGF $\beta 1$ can be inhibited with antisense oligonucleotides ${ }^{4}$ and neutralizing antibodies, ${ }^{5}$ resulting in attenuated left ventricular remodeling and reduced interstitial fibrosis. ${ }^{6}$

Yet, the contribution of TGF $\beta 1$-SMAD signaling to the development of cardiac fibrosis as a function of MI extent and zonal proximity to the infarct is unknown. ${ }^{2}$ In addition, the issue of whether these pathways can be manipulated with gene therapy is largely unclear and controversial. ${ }^{6}$ Moreover, the impact of gene therapy acting on cellular structures to modify the structural integrity of myocytes is a new area of research.

The cardiac extracellular matrix is composed mostly of fibrillar collagen type I (tensile strength) and type III (elasticity and structural integrity). ${ }^{7}$ Both types are synthesized by cardiac myofibroblasts wherein a procollagen (a prerequisite of fibrillar collagen) forms in the sarcoplasmic reticulum and is dependent on the function of sarcoplasmic reticulum calcium adenosine triphosphatase $2 \mathrm{a}$ (SERCA2a). In heart failure, the ratio of type I to type III collagen, as well as the ratio of mature to de novo collagen, is altered. ${ }^{8}$ However, the changes in these ratios after ischemic injury, and the kinetics of de novo collagen deposition in border and remote zones of infarcted hearts, are not yet understood. ${ }^{9}$
A hallmark of heart failure is abnormal intracellular calcium ion $\left(\mathrm{Ca}^{2+}\right)$ handling and down-regulation of SERCA2a. Failing hearts have a dysfunction in excitationcontraction coupling and deficient SERCA2a uptake. $\mathrm{We}^{10}$ and others ${ }^{11}$ have demonstrated that the normalization of SERCA2a expression improves cardiac function in the infarcted heart. Given that SERCA2a closely controls intracellular $\mathrm{Ca}^{2+}$, we hypothesized that the effects of overexpression of SERCA2a are linked with MI-stimulated fibrogenesis.

\section{METHODS}

\section{Animals}

All animals received humane care in compliance with the requirements of the National Institutes of Health and the local institutional animal care and use committee. Dorsett male sheep $(\mathrm{n}=26)$ weighing $46.1 \pm 3.6 \mathrm{~kg}$ were used. All animals were divided into 4 groups: group $1(n=6)$ had animals with small MI, without clinical signs of heart failure, after proximal ligation of the first branch of the circumflex artery; group $2(n=10)$ had animals with large MI, with clinical heart failure, after proximal ligation of the first 2 branches of the circumflex artery; group $3(n=7)$ had animals with large MI followed by gene construct (adeno-associated viral vector, serotype 1 [AAV1]. cytomegalovirus.SERCA2a) transfer using MCARD after 4 weeks (large MI/SERCA); and group $4(n=3)$ was control animals, with tissue collected for molecular studies before any procedure was performed. Animals in groups 1 to 3 were killed at 12 weeks. All of the data presented in this article are new; however, we have published some data from subsets of these animals previously. ${ }^{12,13}$

\section{Vector Production}

A recombinant single-stranded AAV1 encoding SERCA2a, under the control of the human immediate early cytomegalovirus gene promoter with a splice donor/acceptor sequence was used. A polyadenylation signal from the human globin gene was constructed in a validated preclinical grade system. This process resulted in high-quality super samplingAAV1. cytomegalovirus. SERCA2a titers, using the Penn Vector Core (University of Pennsylvania, Philadelphia, Pa).

\section{Surgical Procedures and Gene Delivery}

For the infarct model, surgical details of the creation of small and large infarcts have been described, ${ }^{10,12}$ as have those of the MCARD procedure. ${ }^{10,14}$ We briefly describe the main features. The heart was isolated, and closed-loop cardiac circuit flow was initiated. The virus solution consisting of $10^{13}$ genome copies of super samplingAAV1.CMV.SERCA2a was injected into the coronary sinus catheter and recirculated. The circuit was flushed to wash out residual vector, and the chest was closed. All animals received postoperative veterinary intensive care unit management.

\section{Analyses and Assessments}

Magnetic resonance imaging (Signa LX, GE Healthcare, Chalfont St Giles, United Kingdom) acquisition and analysis of cardiac hemodynamics were conducted for each animal at various time points. ${ }^{15}$ More details are described in Appendix 1. For messenger ribonucleic acid analysis, total ribonucleic acid was isolated using TRIzol Reagent (Invitrogen, Carlsbad, Calif), and complementary deoxyribonucleic acid synthesis was performed as previously described. ${ }^{16}$ Western blots were done as previously described $^{12}$ and normalized to glyceraldyhde-3-phosphate dehydrogenase 
TABLE 1. Hemodynamics data, all (Mean \pm STD). Baseline and 12-week hemodynamics for animals in each group

\begin{tabular}{|c|c|c|c|c|c|c|}
\hline \multirow[b]{2}{*}{ Measure } & \multicolumn{3}{|c|}{ Baseline } & \multicolumn{3}{|c|}{12 weeks after MI } \\
\hline & Large MI/SERCA & Small MI & Large MI & Large MI/SERCA & Small MI & Large MI \\
\hline $\mathrm{CO}(\mathrm{mL} / \mathrm{min})$ & $2984 \pm 325$ & $2650 \pm 575$ & $2931 \pm 397$ & $2732 \pm 581^{*}, \dagger$ & $2246 \pm 352^{*}, \ddagger$ & $1861 \pm 254 \ddagger$ \\
\hline EDV & $49.8 \pm 5.0$ & $46.4 \pm 10.0$ & $51.4 \pm 10.5$ & $83.2 \pm 25^{*}, \dagger, \uparrow$ & $56.2 \pm 11.6^{*}$, & $94.8 \pm 30.3 \dagger$ \\
\hline ESV & $19.5 \pm 2.6$ & $21.0 \pm 9.6$ & $22.1 \pm 8.3$ & $48.1 \pm 20^{*}, \ddagger$ & $32.5 \pm 10.3^{*}, \ddagger$ & $66.2 \pm 24.3 \dagger$ \\
\hline $\mathrm{EF}(\%)$ & $60.6 \pm 7.1$ & $56.4 \pm 10.9$ & $58.0 \pm 10.3$ & $43.3 \pm 11.1 *, \ddagger$ & $42.6 \pm 6.9^{*}, \ddagger$ & $31.0 \pm 7.8 \dagger, \ddagger$ \\
\hline SVi & $27.1 \pm 5.6$ & $22.6 \pm 6.5$ & $24.5 \pm 4.7$ & $30.1 \pm 7.4^{*}, \dagger$ & $19.4 \pm 5.5$ & $20.9 \pm 6.0$ \\
\hline Wall thickness & $11.1 \pm 1.6$ & $11.8 \pm 4.9$ & $10.5 \pm 1.8$ & $13.8 \pm 1.3 \ddagger$ & $14.0 \pm 1.1 \ddagger$ & $12.6 \pm 1.6$ \\
\hline Wall thickening $(\%)$ & $26.9 \pm 8.2$ & $20.5 \pm 11.3$ & $26.5 \pm 10.5$ & $17.1 \pm 6.3^{*}, \ddagger$ & $18.6 \pm 14.7$ & $7.4 \pm 10.9 \ddagger$ \\
\hline $\mathrm{dP} / \mathrm{dt}$ maximum $(\mathrm{mm} \mathrm{Hg} / \mathrm{s})$ & $1151 \pm 243$ & $1246 \pm 138$ & $1165 \pm 154$ & $1084 \pm 193$ & $1237 \pm 397$ & $931 \pm 91$ \\
\hline $\mathrm{dP} / \mathrm{dt}$ minimum $(\mathrm{mm} \mathrm{Hg} / \mathrm{s})$ & $-1769 \pm 574 \dagger$ & $-1235 \pm 230^{*}$ & $-1856 \pm 444 \dagger$ & $-1218 \pm 93$ & $-1318 \pm 256$ & $-1259 \pm 161 \ddagger$ \\
\hline Heart rate $(\mathrm{bpm})$ & $93 \pm 13$ & $95 \pm 11$ & $94 \pm 9$ & $95 \pm 13$ & $95 \pm 13$ & $95 \pm 9$ \\
\hline Hematocrit $(\%)$ & $31 \pm 5$ & $31 \pm 4$ & $31 \pm 4$ & $29 \pm 5$ & $29 \pm 4$ & $27 \pm 2$ \\
\hline Mean arterial pressure $(\mathrm{mm} \mathrm{Hg})$ & $94 \pm 8$ & $90 \pm 13$ & $94 \pm 9$ & $95 \pm 11$ & $92 \pm 9$ & $94 \pm 7$ \\
\hline
\end{tabular}

$M I$, Myocardial infarct; $S E R C A$, sarcoendoplasmic reticulum calcium adenotransphosphatase; $C O$, cardiac output; $E D V$, end diastolic volume; $E S V$, end systolic volume; $E F$, ejection fraction; $S V i$, stroke volume index; $d P / d t$, rate of change of pressure. $* P<.05$ versus large MI. $\dagger P<.05$ versus small MI. $\ddagger P<.05$ versus baseline of same group.

(sc-48166; Santa Cruz Biotechnology, Dallas, Tex; details are available in Appendix 1).

Quantification of collagen content and distinguishing between De Novo and Mature collagen were performed using Herovici's polychrome. ${ }^{17}$ Details are available in Appendix 1. After localization of the heart and acquisition of electrocardiographically gated cine images, gadoliniumdiethylenetriaminepentacetate was administered to the animal. To quantify the precise amount of fibrotic tissue, hyperenhanced areas were manually traced on the short-axis images. Scar tissue was expressed as a percentage of the left ventricle. ${ }^{15}$

Left ventricle sections were stained with Sirius Red (Abcam, Cambridge, Mass). Quantification of fibrosis was performed with computer-assisted morphometry measurement using a digital camera for microscopy. Each field was scanned with a computer-generated microscale and analyzed under blinded conditions, using 9 to 11 randomly selected tissue sections from each of the hearts, using image analysis software. ${ }^{18}$ A minimum of 10 random fields for border zone (BZ) and remote zone (RZ) were utilized for electron microscopy analysis of myofibrillar disruption in each group. ${ }^{19}$ Details are available in Appendix 1.

\section{Myocardial Infarct Size Quantification}

After harvesting, the left ventricle was dissected and photographed. The endocardial surface and the infarcted scar were traced onto a transparency and quantified using computed planimetry. Sections were embedded in paraffin for immunohistochemistry; for molecular and genetic studies, they were stored at a temperature of $-80^{\circ} \mathrm{C}$ until use.

Angiotensin II and $\mathrm{AT}_{1} \mathrm{R}$ expression of angiotensin II and angiotensin II type I receptor are described in Appendix 1. After heart harvesting and sectioning through the left ventricle, the scarred infarct zone (IZ) was identified as discolored fibrous tissue in the posterolateral part of the left ventricle. Samples from a 1-cm zone extending from the outer discolored sections were taken as BZ. Right-ventricular wall myocardium was identified as RZ.

\section{Statistical Analysis}

Most data were presented as average \pm standard error of the mean. The Kolmogorov-Smirnov test for normality was applied to each data set before further statistical testing was conducted. A single analysis of variance was performed across time for each parameter, then paired $t$ tests were used to assess for difference between any 2 time points, or between groups at the same time point. Statistical comparisons for a whisker plot were made based on 1-way analysis of variance comparing the median $(50 \%$ percentile) with a Tukey multiple comparison test.

\section{RESULTS \\ Hemodynamics}

Hemodynamics at baseline and 12 weeks after MI are listed in Table 1. Baseline cardiac function did not differ significantly between the groups. At 12 weeks, hearts with large MI revealed decreased ejection fraction $(31.0 \% \pm 7.8 \%)$ compared with the group with large MI who had SERCA2a delivery $(43.3 \% \pm 11.1 \%)$ and the group with small MI $(42.6 \% \pm 6.9 \%)$, both $P<.05$. Significant improvements in cardiac output, end diastolic volume, end systolic volume, stroke volume index, and wall thickening were observed in the large MI with SERCA group, compared with the large MI group. Infarct size for large MI $(20.4 \% \pm 2.6 \%)$ and for large MI with SERCA $(19.8 \% \pm 2.4 \%)$ did not differ significantly from each other but were significantly greater than that for small MI $(7.3 \% \pm 0.7 \%)$, both $P<.05$.

\section{Expression of SERCA2a}

Western blot analysis showed a significant increase in SERCA2a protein levels, especially in large MI with SERCA animal BZ $(0.28 \pm 0.018 \mathrm{RU})$, compared with small MI $(0.14 \pm 0.023 \mathrm{RU})$ and large MI $(0.16 \pm 0.045$ RU) BZ, $P<.05$. The same trend was found in the IZ, but data did not reach significance $(P>.05)$ (Figure 1). At 12 weeks, all animals had detectable levels of transgene in the BZ $(4372 \pm 156.7$ genome copies per $100 \mathrm{ng}$ DNA) and IZ (1524 \pm 109.5 genome copies). This was significantly higher than in the RZ $(246 \pm 99.8$ genome copies) and liver (607 \pm 53.9 genome copies).

The TGF $\beta 1$ pro-fibrotic signaling genes (TGF $\beta 1$, TGF $\beta$ RII, SMAD3, and collagen alpha 1 type 1) were examined from cardiac tissue isolated from various MI zones (IZ, BZ, and RZ) among the 3 experimental groups. Signaling components of $\mathrm{TGF} \beta 1$ were significantly up-regulated in large MI, compared with small MI, and 


\section{Resultant SERCA2a Expression Levels Post MI}

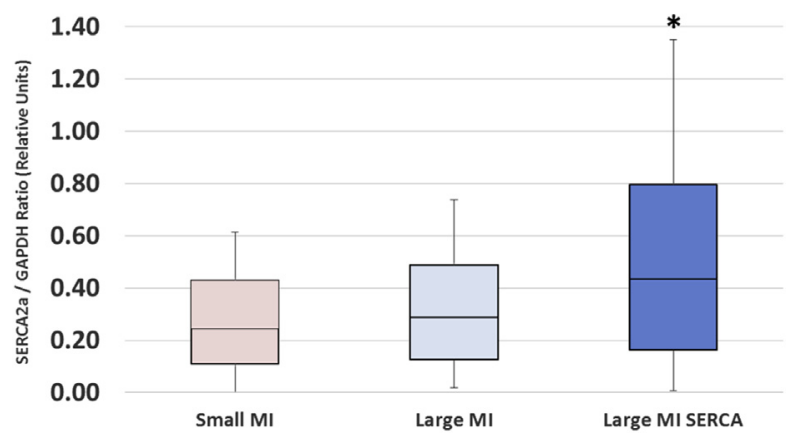

FIGURE 1. Western blot quantifying SERCA2a protein expression in the $\mathrm{BZ}$ of small MI, large MI, and large MI with SERCA groups. SERCA2a, Sarcoplasmic reticulum calcium adenosine triphosphatase isoform 2a; $M I$, myocardial infarction; GAPDH, glyceraldehyde-3-phosphate dehydrogenase. ${ }^{*} P<.01$, versus small MI, large MI.

SERCA2a overexpression mitigated these molecular alterations (Figure 2, A-C). Up-regulation of the TGF $\beta 1$ signaling cascade was particularly marked in the IZ (scar tissue), but many of these genes were up-regulated in the $\mathrm{BZ}$ and RZ of large MI animals. Western blots of TGF $\beta$ RII and collagen alpha 1 type 1 in the IZ and BZ revealed increased expression in both small and large MI compared with control and large MI with SERCA.

\section{Plasma Angiotensin II and Myocardial $\mathrm{AT}_{1} \mathrm{R}$}

Angiotensin II is able to directly stimulate fibrogenesis in the heart. In addition, the actions of angiotensin II can be inhibited with $\mathrm{AT}_{1} \mathrm{R}$ antagonists, which are currently used in heart failure therapy; thus, these represent important parameters to assess after gene therapy. Angiotensin II and $\mathrm{AT}_{1} \mathrm{R}$ expression, assessed by immunohistochemistry, both increased significantly compared with control in small and large MI. Delivery of SERCA2a significantly reduced plasma angiotensin II levels and myocardial $\mathrm{AT}_{1} \mathrm{R}$ expression compared with large MI (Figure E1, $A-F$ ).

\section{Myofibroblasts and Fibronectin}

Ventricular fibroblasts normally maintain low turnover of fibrillar collagens but transform to an activated myofibroblast phenotype (myoFb) in response to injury, wherein $\alpha$ SMA and fibronectin expression are markers of this transformation. $\alpha$ SMA protein expression was significantly increased in the BZ of large MI $(P<.05)$ and small MI $(P<.05)$ groups compared with large MI with SERCA2a and control (Figure 3,A). Furthermore, fibronectin protein expression was significantly increased in large $\mathrm{MI}$ $(P<.05)$ compared with large MI with SERCA, with the latter showing a nonsignificant decrease compared with both control and small MI (Figure 3, B). This same trend
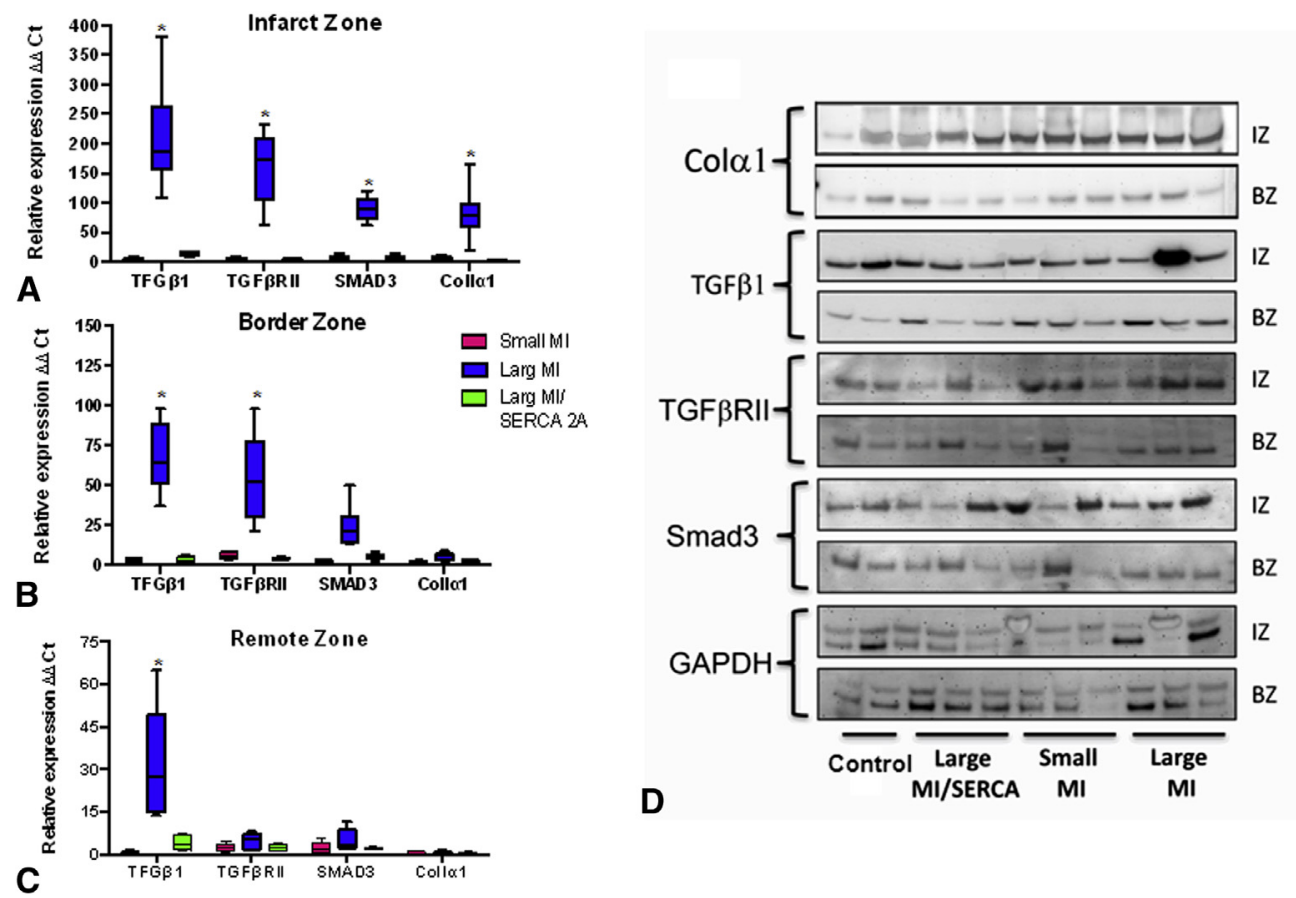

FIGURE 2. A-C, Messenger ribonucleic acid expression levels of TGF $\beta 1$ signaling components and downstream target [Col $\alpha 1$ (I)] were assessed in heart tissue from: (A) IZ; (B) BZ; and (C) RZ. D, Protein content in IZ and BZ of Col $\alpha 1$ (I), TGF $\beta 1$, TGF $\beta$ RII, and Smad3, as measured by Western blot for control, large MI with SERCA, small MI, and large MI groups. GAPDH protein expression measured for normalization. TGF $\beta$, Transforming growth factor beta; Smad, an intracellular signaling protein family; Col $\alpha$, Collagen alpha 1 type 1; GAPDH, glyceraldehyde-3-phosphate dehydrogenase; MI, myocardial infarction; SERCA, sarcoplasmic reticulum calcium adenosine triphosphatase; $I Z$, infarct zone; $B Z$, border zone. * $P<.05$ versus small MI, large MI with SERCA2a. 

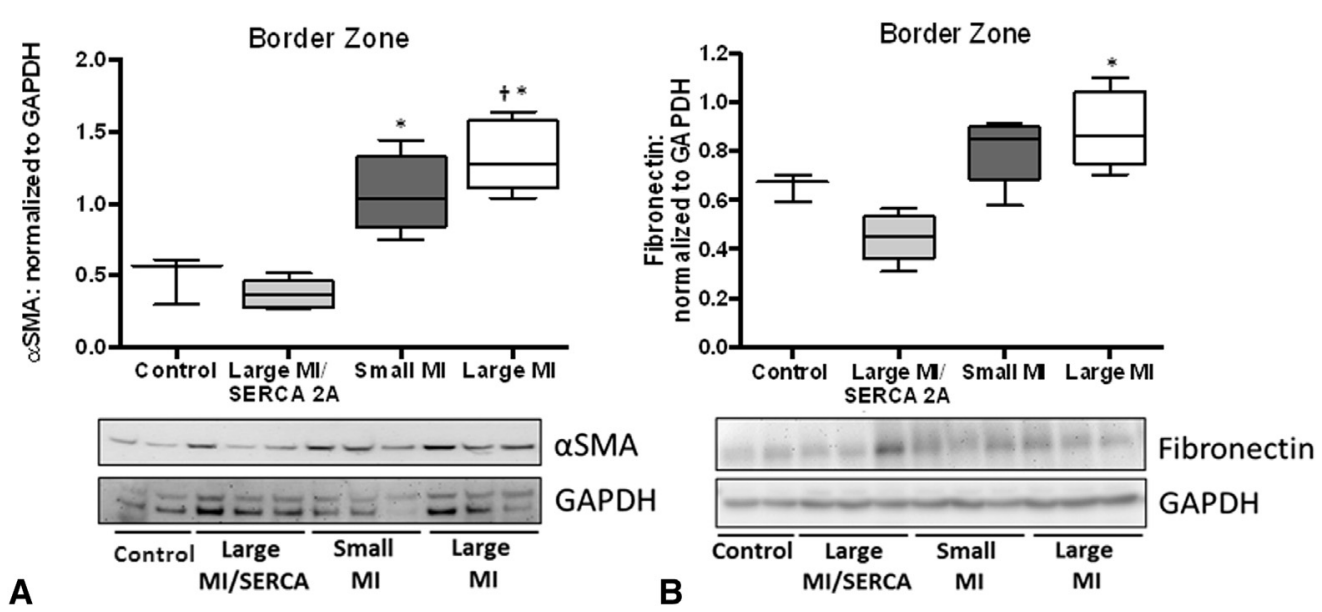

FIGURE 3. Changes in (A) $\alpha$ SMA protein as well as (B) fibronectin protein, measured using Western blot, normalized to GAPDH. $\alpha S M A$, alpha smooth muscle actin; GAPDH, glyceraldehyde-3-phosphate dehydrogenase; $M I$, myocardial infarction; SERCA, sarcoplasmic reticulum calcium adenosine. $* P<.05$ versus large MI with SERCA. $\dagger P<.05$ versus control.

was observed in IZ and RZ; however, the decrease was not significant $(P>.05)$.

\section{New Collagen}

We performed multispectral imaging of Herovici stained samples to differentiate between mature and de novo collagen synthesis. The degree of myocardial collagen deposition was quantified in heart tissue from each zone of damage (IZ, BZ, and RZ) for each experimental group (small MI, large MI, large MI with SERCA). A significant increase was found in the ratio of de novo (blue staining) to mature collagen (red staining) (Figure $4, J$ ) in all zones of the large MI animals (Figure 4, $B, E, H$ ) compared with small MI (Figure 4, $A, D, G$ ). Further, overexpression of SERCA2a reduced the ratio of de novo (blue fibrils) to mature (red fibrils) collagen in IZ and BZ (Figure 4, $C, F$ ) compared with large MI (Figure 4, B,E). Overall, less collagen fibril deposition in RZ occurred in large MI with SERCA; thus, limited amounts of mature collagen were observed in this zone (Figure 4,I). These data suggest a persistent fibrotic response (ie, increased deposition of new collagen fibrils) in large MI, whereas fibrosis in the small MI and large MI with SERCA has been mitigated.

\section{Myocardial Structure}

The significant difference was in the specimens from the BZ between the MI with SERCA group and large MI. In the MI with SERCA group at gross histology, myocytes seemed nearly normal, with nuclei in the center and widely spaced intercalated discs; signs of ischemic injury were less. In the $\mathrm{BZ}$ of the large MI group, transmission electron microscopy revealed substantial cardiac damage associated with pronounced sarcomere fragmentation, including longitudinal disruption and disorganization of myofibrils, as well as disrupted Z-discs.
Mitochondrial damage was indicated by indistinct, fragmented, or vesiculated cristae in both the BZ and RZ of the large MI specimens. Notable twin $\mathrm{T}$ tubule dilatation was present in all BZ fields, but only in the large MI of the RZ fields. In large MI with SERCA and small MI samples, morphologic structure was largely preserved (Figure 5, $A-F)$. Semiquantitative analysis showed increased levels of myofibrillar disruption in large MI BZ, but not small MI or large MI with SERCA BZ (Figure 5, G).

\section{DISCUSSION}

We demonstrate that MCARD-mediated SERCA2a gene delivery disrupts activation of the TGF $\beta 1 /$ SMAD signaling cascade, inhibiting de novo collagen synthesis and downregulating angiotensin II and $\mathrm{AT}_{1} \mathrm{R}$. A growing body of evidence from studies conducted in the heart indicates that post myocardial infarction-activated TGF $\beta 1$ signaling triggers a system involving SMAD proteins, which are phosphorylated and subsequently translocated to the nucleus to regulate target gene transcription. ${ }^{20}$ We found that TGF $\beta 1$ signaling genes are dramatically up-regulated in large MI in all myocardial zones compared with small MI and large MI with SERCA groups. In response to the fibrogenic stimuli resulting from ischemic stress, cardiac fibroblasts switch to a myofibroblast phenotype and express $\alpha$ SMA as well as fibronectin. We found that in the large MI with SERCA group, the expression of $\alpha \mathrm{SMA}$ and fibronectin was markedly decreased relative to other groups.

From our hypothesis, the mechanism seems to be as follows: The overexpression of SERCA2a in ischemic cardiomyopathy mitigates the otherwise MI-associated cytosolic $\mathrm{Ca}^{2+}$ overload, prolongation of the cytosolic $\mathrm{Ca}^{2+}$ transient time, and the consequent increase in end-diastolic $\mathrm{Ca}^{2+}$ concentration ${ }^{11}$ (Figure 6). Developing cytosolic $\mathrm{Ca}^{2+}$ overload increases the activity of $\mathrm{Ca}^{2+}$ 

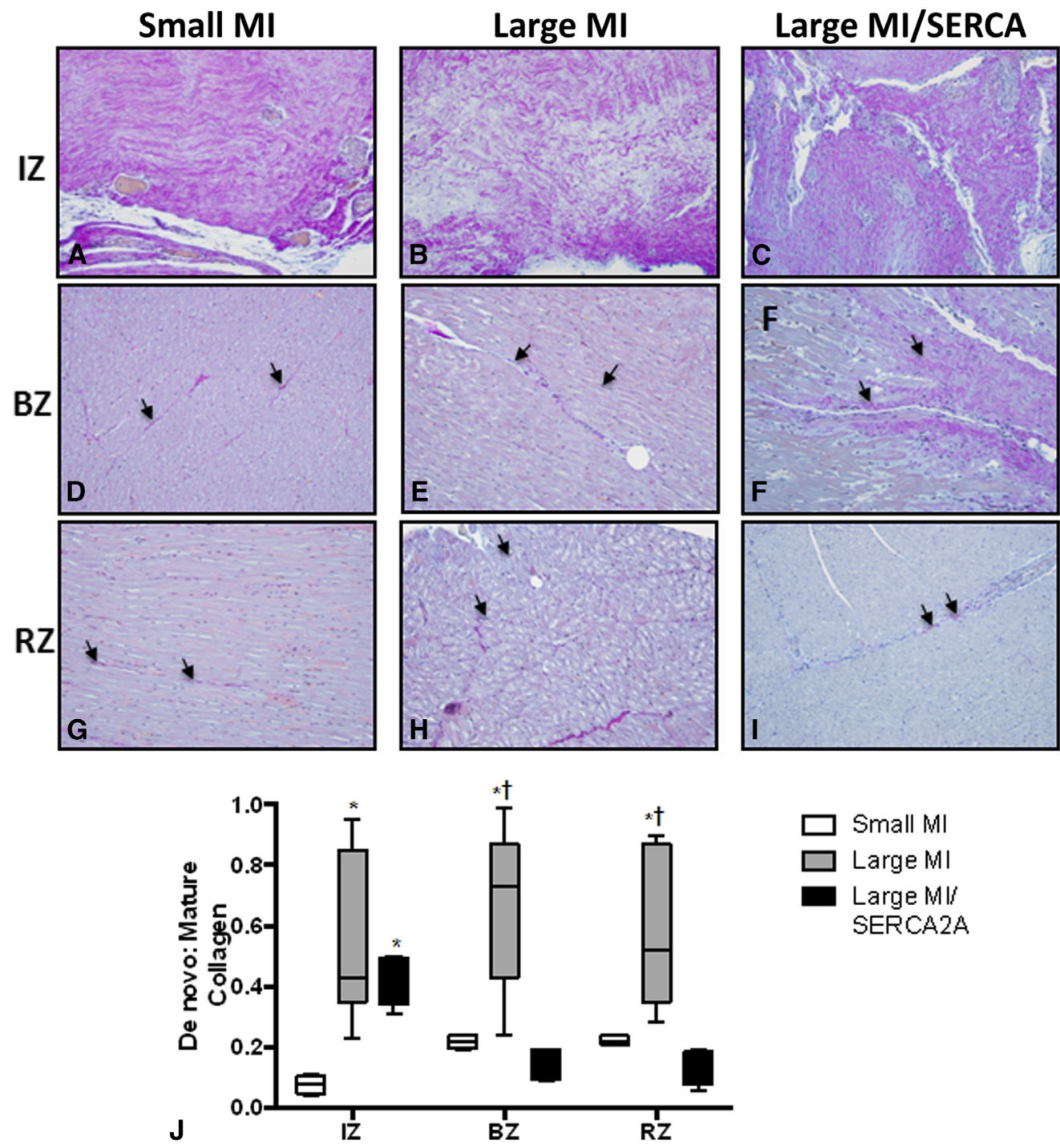

dependent serine/threonine phosphatase calcineurin. ${ }^{21}$ The activated calcineurin binds and dephosphorylates calcium-sensitive, calcineurin-nuclear factor of the activated T-cell, ${ }^{21,22}$ which translocates from the cytosol to the nucleus and interacts directly ${ }^{23,24}$ with the cardiac transcription factor GATA4. This process triggers a signal transduction pathway: Renin splits the protein angiotensinogen, producing angiotensin $\mathrm{I}$, which is converted $^{24}$ into angiotensin II.

In cardiac fibroblasts, angiotensin II stimulates expression of extracellular matrix proteins, ${ }^{25}$ such as $\alpha$ SMA and fibronectin, mainly through $\mathrm{AT}_{1} \mathrm{R}$. Strong evidence indicates that angiotensin II regulates $\mathrm{TGF} \beta 1$ expression in adult ventricular cardiomyocytes. ${ }^{26,27}$ We postulate that
SERCA2a overexpression normalizes calcium signaling and decreases activation of angiotensin II, providing a mechanism for the effect of SERCA2a overexpression on the TGF $\beta 1-S M A D$ pathway and attenuation of fibrosis. These data confirmed that SERCA2a overexpression reduces the secretion of both fibrogenic mediators, providing evidence that SERCA2a overexpression diminishes fibroblast activation.

The question of whether advanced fibrotic tissue can be reverted to normal tissue architecture remains controversial. If fibrosis is accompanied with changes in the mechanical environment, including tissue segment length and tension, leading to disruptive changes in myofibrils with increased end systolic and diastolic dimensions, then full reversal is 

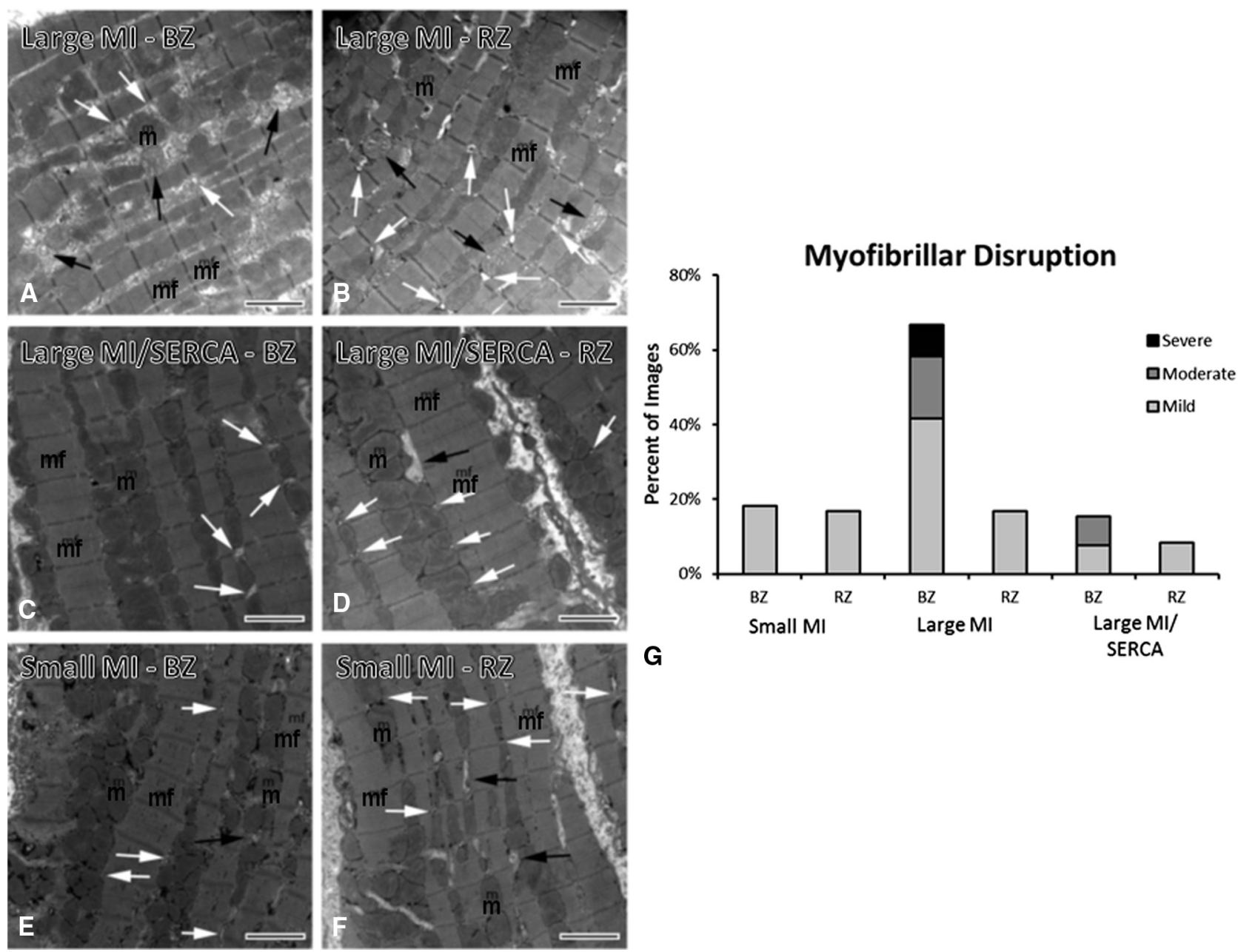

FIGURE 5. A-F, Transmission electron microscopy images of BZ and RZ tissue from each group. Examples of $m$ and mf with clearly delineated sarcomeres are labeled. Varying degrees of mitochondrial fragmentation and cristae destruction are shown (black arrows) along with twin T tubules (white arrows). Images $\times 10,500$ magnified, scale bar: $2 \mu \mathrm{m}$. G, Semiquantitative analysis of myofibrillar disruption seen in images A-F. MI, Myocardial infarction; $B Z$, border zone; $m$, mitochondria; $m f$, myofibrils; $R Z$, remote zone; $S E R C A$, sarcoplasmic reticulum calcium adenosine.

not possible. ${ }^{28}$ As is well known, the sarcoplasmic reticulum is closely associated with the myofibrils. The action potential spreads along the sarcolemma and transverse tubular system into the myofibrils, activating the ryanodine receptor that releases $\mathrm{Ca}^{2+}$ from the sarcoplasmic reticulum. Fibrogenesis changes these processes. So we sought to trace the impact of fibrosis on the structural integrity of myofibrils, and we found that myocardial structural integrity is preserved after SERCA2a gene therapy.

Collagen accumulation is an integral part of fibrosis, resulting from a shift in the balance between collagen synthesis and degradation. The expression of these collagens in the ischemic cardiac muscle remains elevated long term. ${ }^{29}$ Reversal of fibrosis is prevented by incomplete extracellular matrix degradation when the appropriate cellular mediators are no longer present. ${ }^{30}$ Area of fibrosis assessed by magnetic resonance imaging and quantitative morphometry demonstrated no significant difference between the large MI and the large MI with SERCA groups at 12 weeks. However, the ratio of de novo to mature collagen was significantly different in the BZ and RZ. Thus, the SERCA gene is associated with a previously undemonstrated alteration of the composition of the cardiac extracellular matrix.

Infarct expansion includes the recruitment of the adjacent BZ. This fully perfused, normally contractile myocardium undergoes advanced remodeling that leads to heart failure. Many of the molecular processes taking place in the BZ are not well defined. ${ }^{31}$ Preventing the breakdown of the extracellular matrix could stiffen the IZ, arresting infarct expansion and remodeling. Gene therapy with MCARD with SERCA2a in developing heart failure significantly increases gene delivery to the $\mathrm{BZ}$, restores contractile function, and mitigates fibrosis in this zone. 


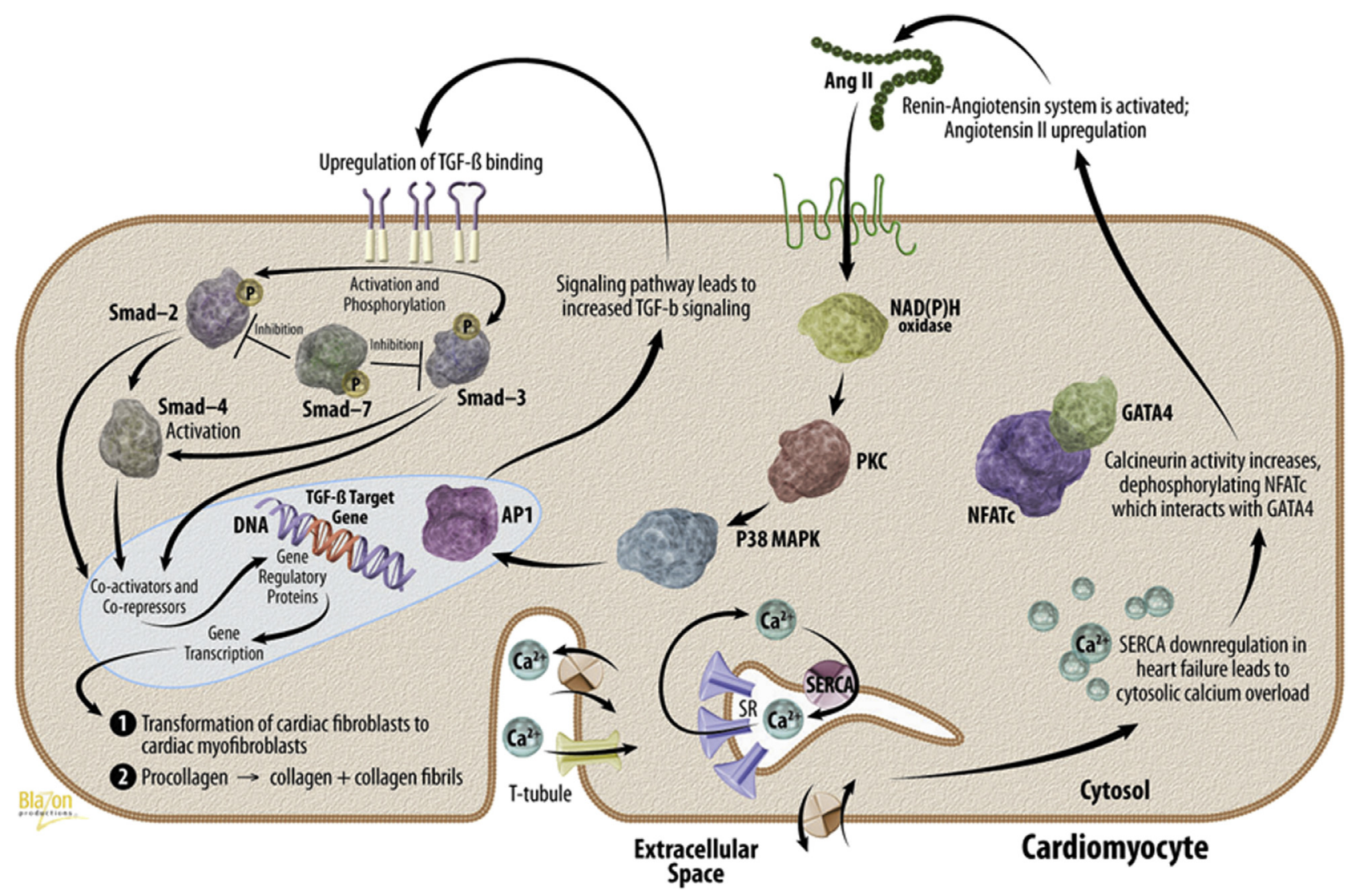

FIGURE 6. Proposed mechanism of action from initial $\mathrm{Ca}^{2+}$ imbalance due to SERCA2a down-regulation through Ang II and TGF- $\beta$ signaling to fibrosis. $T G F \beta$, Transforming growth factor beta; Ang II, angiotensin II; Smad, SMAD family signal transduction proteins; $N A D P H$, nicotinamide adenine dinucleotide phosphate; NFATc, nuclear factor of activated T-cells, cytoplasmic; GATA4, GATA family zinc finger transcription factor 4; DNA, deoxyribonucleic acid; AP1, transcription factor; P38 MAPK, p38 mitogen-activated protein kinases; PKC, protein kinase C; SERCA2a, sarcoplasmic reticulum calcium adenosine triphosphatase isoform 2a; $M I$, myocardial infarct.

Our ovine model of large MI shows extensive LV remodeling in the IZ and BZ, accompanied by a permanent fibrogenic response. Contrary to previous data obtained in a murine model showing that fibrosis is independent of the severity of ischemia, ${ }^{32}$ fibrotic signaling ceases after initial scar formation in our small MI model-a major difference in fibrotic response due to infarct size. Because of the lack of significant LV remodeling in the small MI group, we did not administer gene therapy under this paradigm. These data provide novel insights as to why, in the presence of a small injury, remodeling is compensatory and limited, whereas after a larger insult, it is progressive and maladaptive.

Myocardial infarction is associated with dynamic changes in myocytes and fibroblasts and in the composition of the extracellular matrix in all cardiac zones. Many studies have demonstrated that the scar and BZ are metabolically active tissues with phenotypic modulation of fibroblasts, secretion of extracellular matrix proteins, and activation of angiogenic pathways.

The highly efficient cardiac-specific MCARD delivery platform may have been vital in achieving sufficiently high SERCA2a expression to produce these results. The MCARD with SERCA2a gene delivery may be a translatable approach to limit post-MI remodeling by halting the fibrogenic response. We chose to perform gene delivery at 4 weeks after MI, for the following reasons: First, at this time, the proliferative and maturation processes of fibrogenesis overlap each other. ${ }^{33}$ Myofibroblasts begin to appear early after infarction, remain abundant over 4 weeks, and are still present in the infarcted heart at week 8 after MI. ${ }^{29}$ Next, the TGF- $\beta$ system receptors and downstream signaling components are elevated for up to 8 weeks after $\mathrm{MI},{ }^{34}$ and the plateau of AAV1 expression occurs at 4 to 6 weeks after viral infection in the cardiomyocytes. Finally, we wanted to eliminate all side effects associated with the surgical creation of MI.

\section{Limitations}

We did not use a small MI with MCARD group, because preliminary data showed no up-regulation of the TGF- $\beta$ with SMAD system or angiotension II in small MI, as had been expected. We did not incorporate a control group 
with MCARD-null vector, as a result of limited resources; that will be clarified by further studies. However, we believe that it is highly unlikely that the MCARD procedure itself is responsible for the dramatic attenuation of fibrogenesis observed with overexpression of SERCA2a. Breakdown of the extracellular matrix and collagen turnover after myocardial infarction occurs with many matrix metalloproteinases, zinc-dependent enzymes, interleukins, etc., and assaying every signaling pathway involved in fibrogenesis is very difficult, with or without gene therapy.

The mechanism responsible for fibrosis is still not well understood and may involve either a direct effect of stretch or a diffusion of signals that originates in the ischemic area through the extracellular matrix. Fibroblasts and myocytes seem to be closely connected via intracellular communications in cardiac injury; thus, we cannot completely eliminate the role of the myocyte-fibroblast interrelationship in the event of fibroblast proliferation/activation and extracellular matrix turnover. For the RZ, we chose the right ventricle, the most distant area from infarction that is not subject to the same stress as the IZ or BZ undergoing geometric distortion and infarct expansion. This choice partly explains the low gene expression given the anatomic pattern of the coronary venous drainage in the sheep heart.

\section{Conflict of Interest Statement}

Roger J. Hajjar, MD, is the scientific founder of Celladon, Inc, which is developing the AAV1.SERCA gene for therapeutic purposes. All other authors have nothing to disclose with regard to commercial support.

We acknowledge the Gene Therapy Resource Program (GTRP); Rachel L. Kaplan, BA for excellent technical assistance; Tracy L. Walling, BS for Herovici and histology analysis; Einar Heiberg, $\mathrm{PhD}$ for cardiac magnetic resonance imaging software; Kim Mihalko, DVM and Karen Fay, BS for animal care, Nury Steuerwald, PhD and Judy Parsons, MS for immunoblotting support, and Daisy Ridings, $\mathrm{PhD}$ for electronic microscopy support.

\section{References}

1. Mann DL, Bristow MR. Mechanisms and models in heart failure: the biomechanical model and beyond. Circulation. 2005;111:2837-49.

2. Dobaczewski M, Chen W, Frangogiannis NG. Transforming growth factor (TGF)-beta signaling in cardiac remodeling. J Mol Cell Cardiol. 2011;51:600-6.

3. Yarbrough WM, Mukherjee R, Ikonomidis JS, Zile MR, Spinale FG. Myocardial remodeling with aortic stenosis and after artic valve replacement: mechanisms and future prognostic implications. J Thorac Cardiovasc Surg. 2012;143:656-64.

4. Akagi Y, Isaka Y, Arai M, Kaneko T, Takenaka M, Moriyama T, et al. Inhibition of TGF-beta 1 expression by antisense oligonucleotides suppressed extracellular matrix accumulation in experimental glomerulonephritis. Kidney Int. 1996;50: 148-55.

5. Kuwahara F, Kai H, Tokuda K, Kai M, Takeshita A, Egashira K, et al. Transforming growth factor-beta function blocking prevents myocardial fibrosis and diastolic dysfunction in pressure-overloaded rats. Circulation. 2002;106:130-5.

6. Okada H, Takemura G, Kosai K, Li Y, Takahashi T, Esaki M, et al. Postinfarction gene therapy against transforming growth factor-beta signal modulates infarct tissue dynamics and attenuates left ventricular remodeling and heart failure. Circulation. 2005;111:2430-7.
7. Yarbrough WM, Mukherjee R, Stroud RE, Rivers WT, Oelsen JM, Dixon JA, et al. Progressive induction of left ventricular pressure overload in a large animal model elicits myocardial remodeling and a unique matrix signature. $J$ Thorac Cardiovasc Surg. 2012;143:215-23.

8. Pauschinger M, Knopf D, Petschauer S, Doerner A, Poller W, Schwimmbeck PL, et al. Dilated cardiomyopathy is associated with significant changes in collagen type I/III ratio. Circulation. 1999;99:2750-6.

9. de Jong S, van Veen TA, de Bakker JM, Vos MA, van Rijen HV. Biomarkers of myocardial fibrosis. J Cardiovasc Pharmacol. 2011;57:522-35.

10. Katz MG, Fargnoli AS, Williams RD, Steuerwald NM, Isidro A, Ivanina AV et al. Safety and efficacy of high-dose adeno-associated virus 9 encoding sarcoplasmic reticulum $\mathrm{Ca}(2+)$ adenosine triphosphatase delivered by molecular cardiac surgery with recirculating delivery in ovine ischemic cardiomyopathy. $J$ Thorac Cardiovasc Surg. 2014;148:1065-73.

11. Kho C, Lee A, Hajjar RJ. Altered sarcoplasmic reticulum calcium cyclingtargets for heart failure therapy. Nat Rev Cardiol. 2012;9:717-33.

12. Swain JD, Fargnoli AS, Katz MG, Tomasulo CE, Sumaroka M, Richardville KC et al. MCARD-mediated gene transfer of GRK2 inhibitor in ovine model of acute myocardial infarction. J Cardiovasc Transl Res. 2013;6:253-62.

13. Fargnoli AS, Katz MG, Yarnall C, Isidro A, Petrov M, Steuerwald N, et al. Cardiac surgical delivery of the sarcoplasmic reticulum calcium ATPase rescues myocytes in ischemic heart failure. Ann Thorac Surg. 2013;96: 586-95.

14. Katz MG, Fargnoli AS, Swain JD, Tomasulo CE, Ciccarelli M, Huang ZM, et al. AAV6-BARKct gene delivery mediated by molecular cardiac surgery with recirculating delivery (MCARD) in sheep results in robust gene expression and increased adrenergic reserve. J Thorac Cardiovasc Surg. 2012;143:720-6.

15. Kaandorp TA, Bax JJ, Lamb HJ, Viergever EP, Boersma E, Poldermans D, et al Which parameters on magnetic resonance imaging determine Q waves on the electrocardiogram? Am J Cardiol. 2005;95:925-9.

16. Lakner AM, Walling TL, McKillop IH, Schrum LW. Altered aquaporin expression and role in apoptosis during hepatic stellate cell activation. Liver Int. 2011;31:42-51.

17. Turner NJ, Pezzone MA, Brown BN, Badylak SF. Quantitative multispectral imaging of Herovici's polychrome for the assessment of collagen content and tissue remodelling. J Tissue Eng Regen Med. 2013;7:139-48.

18. Kumar RK. Morphological methods for assessment of fibrosis. Meth Mol Med 2005; 117:179-88.

19. Sherman AJ, Klocke FJ, Decker RS, Decker ML, Kozlowski KA, Harris KR, et al. Myofibrillar disruption in hypocontractile myocardium showing perfusion-contraction matches and mismatches. Am J Physiol Heart Circ Physiol. 2000;278:H1320-34.

20. Wunsch M, Sharma HS, Markert T, Bernotat-Danielowski S, Schott RJ Kremer P, et al. In situ localization of transforming growth factor beta 1 in porcine heart: enhanced expression after chronic coronary artery constriction. J Mol Cell Cardiol. 1991;23:1051-62.

21. Wilkins BJ, Molkentin JD. Calcium-calcineurin signaling in the regulation of cardiac hypertrophy. Biochem Biophys Res Commun. 2004;322:1178-91.

22. Martinez-Martinez S, Redondo JM. Inhibitors of the calcineurin/NFAT pathway. Curr Med Chem. 2004;11:997-1007.

23. Molkentin JD, Lu JR, Antos CL, Markham B, Richardson J, Robbins J, et al. A calcineurin-dependent transcriptional pathway for cardiac hypertrophy. Cell. 1998:93:215-28.

24. Molkentin JD. Calcineurin-NFAT signaling regulates the cardiac hypertrophic response in coordination with the MAPKs. Cardiovasc Res. 2004;63:467-75.

25. Bouzegrhane F, Thibault G. Is angiotensin II a proliferative factor of cardiac fibroblasts? Cardiovasc Res. 2002;53:304-12.

26. Rosenkranz S. TGF-beta1 and angiotensin networking in cardiac remodeling Cardiovasc Res. 2004:63:423-32.

27. Wenzel S, Taimor G, Piper HM, Schluter KD. Redox-sensitive intermediates mediate angiotensin II-induced p38 MAP kinase activation, AP-1 binding activity, and TGF-beta expression in adult ventricular cardiomyocytes. FASEB J. 2001;15:2291-3.

28. Zimmer G, Zimmermann R, Hess OM, Schneider J, Kubler W, Krayenbuehl HP, et al. Decreased concentration of myofibrils and myofiber hypertrophy are structural determinants of impaired left ventricular function in patients with chronic heart diseases: a multiple logistic regression analysis. J Am Coll Cardiol. 1992;20:1135-42.

29. Sun Y, Zhang JQ, Zhang J, Lamparter S. Cardiac remodeling by fibrous tissue after infarction in rats. $J$ Lab Clin Med. 2000;135:316-23. 
30. Wynn TA. Cellular and molecular mechanisms of fibrosis. J Pathol. 2008;214: 199-210.

31. Shimkunas R, Zhang Z, Wenk JF, Soleimani M, Khazalpour M, AcevedoBolton G, et al. Left ventricular myocardial contractility is depressed in the borderzone after posterolateral myocardial infarction. Ann Thorac Surg. 2013; 95:1619-25.

32. Tsuda T, Gao E, Evangelisti L, Markova D, Ma X, Chu ML. Post-ischemic myocardial fibrosis occurs independent of hemodynamic changes. Cardiovasc Res. 2003;59:926-33.
33. Frangogiannis NG. Regulation of the inflammatory response in cardiac repair. Circ Res. 2012;110:159-73.

34. Deten A, Holzl A, Leicht M, Barth W, Zimmer HG. Changes in extracellular matrix and in transforming growth factor beta isoforms after coronary artery ligation in rats. J Mol Cell Cardiol. 2001;33:1191-207.

Key Words: gene therapy, fibrosis, TGFbeta, myocardial infarction

\title{
EDITORIAL COMMENTARY
}

\section{Returning to the bench with adeno-associated virus 1 SERCA2a gene therapy}

\author{
Leora B. Balsam, MD, ${ }^{a}$ and Abe DeAnda, Jr, MD ${ }^{\mathrm{b}}$
}

\footnotetext{
From the a Department of Cardiothoracic Surgery, New York University-Langone Medical Center, New York, NY; and the ${ }^{\mathrm{b}}$ Division of Cardiothoracic Surgery, University of Texas Medical Branch-Galveston, Galveston, Tex. Disclosures: Authors have nothing to disclose with regard to commercial support.

Received for publication Dec 8, 2015; accepted for publication Dec 8, 2015; available ahead of print Jan 16, 2016. Address for reprints: Leora B. Balsam, MD, Department of Cardiothoracic Surgery, NYU-Langone Medical Center, 530 First Ave, Suite 9V, New York, NY 10016 (E-mail: leora.balsam@nyumc.org).

J Thorac Cardiovasc Surg 2016;151:1200-2 $0022-5223 / \$ 36.00$

Copyright (c) 2016 by The American Association for Thoracic Surgery http://dx.doi.org/10.1016/j.jtcvs.2015.12.010
}

The basic science of postinfarct remodeling may not be the most familiar topic for readers of the Journal. Yet the processes that lead to pathologic changes in the form and function of the left ventricle after a transmural myocardial infarction (MI) are fertile areas for research, because current medical and surgical therapies do not avert the process. After a transmural MI, a full-thickness area of myocardium is replaced with fibrotic scar. Regions of the myocardium that border the infarct zone (the "border zone" myocardium) are subjected to stresses that may lead to additional myocyte loss, thereby expanding the zone of injury. With time, a maladaptive process of remodeling can ensue, with ventricular dilatation, increased sphericity, and worsening ejection fraction, leading in some cases to acute and chronic systolic heart failure. Mitral valve regurgitation, secondary to annular dilatation or papillary muscle scarring and posterior leaflet tethering, further contributes to the adverse remodeling process by introducing volume overload and pulmonary hypertension.

Revascularization is the standard approach for acute ST-elevation MI. Early percutaneous coronary intervention and thrombolytic agents have supplanted surgical revascularization for most of these cases. For missed ST-elevation MIs, the role of revascularization is controversial, although

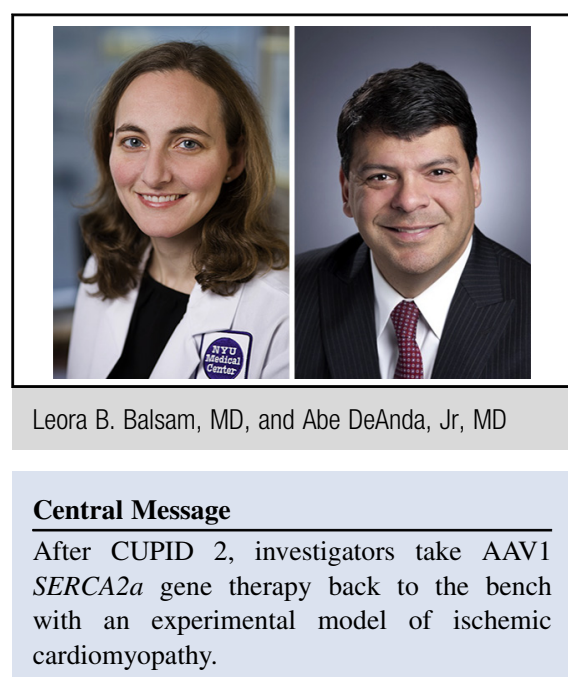

See Article page 1191

late revascularization may protect the border zone myocardium. Other surgical therapies, including mitral repair or replacement for ischemic mitral regurgitation and surgical ventricular restoration for dilated ischemic cardiomyopathy, are treatment options for advanced stages of postinfarct remodeling; in randomized, controlled trials, however, neither has resulted in improved long-term survival. ${ }^{1,2}$

Experimental models of MI have drawn attention to the molecular and cellular pathophysiology of postinfarct remodeling and have attempted to alter or ameliorate the process. Small animal models (primarily in the mouse and rat) have evaluated the impact of genetic and pharmacologic interventions on remodeling after transmural MI from ligation of the left anterior descending coronary artery. Gene-based 


\section{APPENDIX 1. SURGICAL PROCEDURES AND GENE DELIVERY}

Once intubated and sedated, the animal is placed supine, prepped, and draped. Heparin is administered (130 U/kg) and re-dosed to maintain an ACT $>400$ seconds. A median sternotomy is created, and a 2-dimensional-transepicardial echocardiogram is performed prior to and after weaning from cardiopulmonary bypass (CPB). The right carotid artery is then cannulated for systemic perfusion. The aortic root vent, superior vena cava (SVC) cannula and retrograde cardioplegia catheter are placed. The inferior vena cava (IVC) is cannulated; full CPB is initiated; the azygous and hemiazygous veins are ligated; the IVC and SVC are doubly snared; a temporary snare is placed around the middle cardiac vein; vent cannulas are placed into the left ventricular cavity through the apex and into the right ventricle through the outflow tract.

The left ventricular, right ventricular, and aortic root vents are connected to the venous limb of the cardiac venous return circuit. The arterial limb of the cardiac circuit is connected to the coronary sinus catheter. The cardiac circuit is primed with Plegisol (Baxter, Cleveland, Miss [total priming volume approximately $100 \mathrm{cc}])$. The aorta is cross clamped. Cold $\left(4^{\circ} \mathrm{C}\right)$ del Nido cardioplegia $(300 \mathrm{cc})$ is delivered antegrade. The heart is isolated by tightening the SVC and IVC snares, cross clamping the pulmonary artery, and tightening the snare around the middle cardiac vein. With the heart fully decompressed, cardiac circuit flow is initiated briefly ( $\sim 15$ seconds) until the coronary sinus pressure equals $40 \mathrm{~mm} \mathrm{Hg}$. Nitroglycerine $150 \mathrm{mg}$ is infused and allowed to dwell for 2 minutes.

The virus solution is injected into the retrograde catheter and recirculated for 20 minutes, with coronary sinus pressure of $40 \mathrm{~mm} \mathrm{Hg}$, and flow adjusted to maintain a constant coronary sinus pressure. The coronary circuit is flushed antegrade with $1000 \mathrm{cc}$ of Hespan to wash out residual vector. Flow is restored. Rewarming is initiated. The animal is weaned from CPB and closed in standard fashion. All animals are recovered from anesthesia and receive critical postoperative care.

\section{Hemodynamic Evaluation and Cardiac Function Assessment}

The heart was imaged from apex to base with 10 imaging levels. Contrast-enhanced images were acquired approximately 15 minutes after bolus injection of gadolinium $(0.20 \mathrm{mmol} / \mathrm{kg}$ intravenous). Evaluations of cardiac cycles were obtained with cardiac magnetic resonance imaging software. All global and regional hemodynamic measures were obtained directly from the magnetic resonance imaging evaluation. To determine global function, endocardial borders were outlined manually on short-axis cine images with software.

\section{Assessment of Collagen Content by Quantitative Multispectral Imaging of Herovici}

Polychrome-formalin fixed paraffin embedded tissues were sectioned at 4 microns on a Leica (Frankfurt, Germany) RM2125 microtome and air dried overnight. Slides were baked to remove excess paraffin before being deparaffinized with xylene and rehydrated with several changes of graded alcohol to distilled water. Herovici's sections were stained with Weigert's (Hamburg, Germany) Iron hematoxylin and rinsed in running tap water, and placed in working Herovici's solution (saturated aqueous picric acid $/ 0.5 \%$ acid fuchsin $/ 0.025 \%$ methyl blue) for $2 \mathrm{mi}$ nutes followed by a rinse in $1 \%$ acetic acid. The slides were dehydrated with several changes of graded alcohol and cleared with xylene before being cover slipped with Permount (Fisher Scientific, Waltham, Mass). Sections were visualized under light microscope (Olympus [Tokyo, Japan] BX40 with a DP72 camera and Cell Sense software) using x20 magnification. De novo (new, blue staining) to mature (old, red staining) collagen staining was quantified using Image $\mathbf{J}$ software for each zone of damage. Digital images were converted to an RBG stack to separate color channels; threshold was set and maintained to minimize background, and the fraction of blue and red staining was quantified. A ratio was calculated from the measured fraction of blue versus red staining per field. A minimum of 5 random fields for IZ, BZ, and RZ were quantified for each sample.

\section{Electron Microscopy Analysis}

Immediately after removal, samples were placed in Karnovsky's fixative and left for 24 hours at $4^{\circ} \mathrm{C}$. Samples were infiltrated with $1 \%$ aqueous osmium tetroxide in a BioWave Pro microwave, dehydrated in a graded series of ethanol in the BioWave Pro and embedded in Spurr resin in a $70^{\circ} \mathrm{C}$ conventional oven. Ultra-thin sections on copper grids were stained with $2 \%$ uranyl acetate and Sato's lead citrate. Sections were analyzed with a Philips Transmission Electron Microscope (CM 10, MI) operated at $60 \mathrm{kV}$. Digital images were captured with a digital camera system from 4 pi Analysis. All reagents were from Electron Microscopy Sciences (Hatfield, Pa). A minimum of 10 random fields forBZ and RZ were utilized for semiquantitative analysis of myofibrillar disruption in each group. This analysis used a scale of 0 to 3 for disruption: 0 , no disruption; 1 , mild: perinuclear disruption, abnormal glycogen deposits; 2 , moderate intermyofibrillar disruption, large glycogen deposits; and 3, severe: intermyofibrillar disruption with reduced A-bands, severely abnormal glycogen. For each field, one of these disruption groups was assigned.

\section{Histology}

Myocardial injury was assessed through the analysis of stained histological sections of the atria and ventricles. 
Formalin-fixed paraffin-embedded tissues were sectioned at 4 microns on a Leica RM2125 microtome and air dried overnight. Slides were baked in a $60^{\circ} \mathrm{C}$ oven for 20 minutes to remove excess paraffin before being deparaffinized with xylene and rehydrated with several changes of graded alcohol to distilled water. $\mathrm{H} \& \mathrm{E}$ sections were stained with Mayer's hematoxylin for 20 minutes, rinsed with running tap water and stained with Eosin Y for 5 seconds followed by several rinses in $95 \%$ alcohol. Sirius red sections were stained overnight in saturated picric acid with $0.1 \%$ Sirius Red F3BA (Aldrich Chemicals). The next morning slides were removed, washed in $0.01 \mathrm{~N}$ hydrochloric acid, and dehydrated through graded alcohols to xylene, and cover slipped in Permount.

\section{Quantitative Real-Time Polymerase Chain Reaction and Western Blot}

Expression was measured by the CFX96 Real-Time PCR Detection System using $50 \mathrm{ng}$ complementary DNA, gene-specific oligonucleotide primers and IQ SYBR Green Supermix (BIO RAD, Hercules, Calif). The ddCt method was used to calculate relative messenger RNA expression levels as normalized to $\beta$-actin and normal corresponding heart tissue. Western blot for SERCA2a (MA3- 919; Fisher Scientific) was performed on extracts from left ventricular tissue. Western blot for downstream pro-fibrotic markers, $\alpha$-smooth muscle actin (ab5694; Abcam, Cambridge, Mass), TGF $\beta$ receptor II (sc-400; TGF $\beta$ RII, Santa Cruz Biotechnology, Dallas, Tex) and collagen $\alpha 1$ Type 1 (sc- 25974; collagen alpha 1 type 1 , Santa Cruz Biotechnology) were performed on extracts from left ventricular tissue. Western blots were normalized to glyceraldyhde-3-phosphate dehydrogenase (sc-48166; Santa Cruz Biotechnology). Western blot for downstream profibrotic markers, $\alpha$-smooth muscle actin, transforming growth factor-beta receptor II (sc-400), collagen alpha 1(I) (sc-25974), and fibronectin (sc-6953) (all Santa Cruz Biotechnology).
Immunoblots were performed on extracts from infarct zone and/or border zone tissue and normalized to glyceraldyhde-3-phosphate dehydrogenase. Tissues were homogenized on ice using an Omni TH Homogenizer (Omni International, Kennesaw, Ga) in T-PER tissue lysis buffer (Life Technologies) per manufacturer protocol.

\section{Angiotensin II and Angiotensin II Type I Receptor $\left(\mathrm{AT}_{1} \mathrm{R}\right)$}

An enzyme-linked immunosorbent assay for angiotensin II (Ang2 sheep E14A0204, BlueGene, St Petersburg, Fla) was performed on plasma samples from sheep collected at baseline (prior to infarct), and 12 weeks after infarction in small MI, large MI, and large MI with SERCA sheep, per manufacturer protocol.

Expression of $\mathrm{AT}_{1} \mathrm{R}$ (ab18801, Abcam) was assessed by immunohistochemistry. Formalin-fixed paraffin-embedded tissues were sectioned at 4 microns on a Leica RM2125 microtome, picked up on plus-slides and allowed to air dry overnight. Slides were baked in a $60^{\circ} \mathrm{C}$ oven for 20 minutes prior to deparaffination in xylene and rehydration through several changes of graded alcohol to distilled water. Antigen retrieval was performed in citrate $\mathrm{pH}$ 6.0, and blocked with normal horse serum. $\mathrm{AT}_{1} \mathrm{R}$ expression was detected by rabbit polyclonal antibody (ab18801; Abcam) diluted 1:75, incubated overnight at $4^{\circ} \mathrm{C}$, warmed to room temperature, rinsed with phosphate-buffered saline, followed by Anti-rabbit ImmPress (Vector Labs) for 30 minutes, and DAB, followed by Mayer's counterstain. Expression of $\mathrm{AT}_{1} \mathrm{R}$ was measured by ImageJ analysis as number of DAB-stained cells per random field. The images were converted to RGB stack, threshold was set for DAB staining, and the images were converted to binary (black/ white) so only DAB-stained cells were counted. For BZ, $\mathrm{n}=3$ with 5 fields per sample; for large MI with SERCA and small MI, $\mathrm{n}=4$ with 10 fields per sample; and for large MI, $\mathrm{n}=5$ with 10 fields per sample. Whisker plot is used to show distribution. 

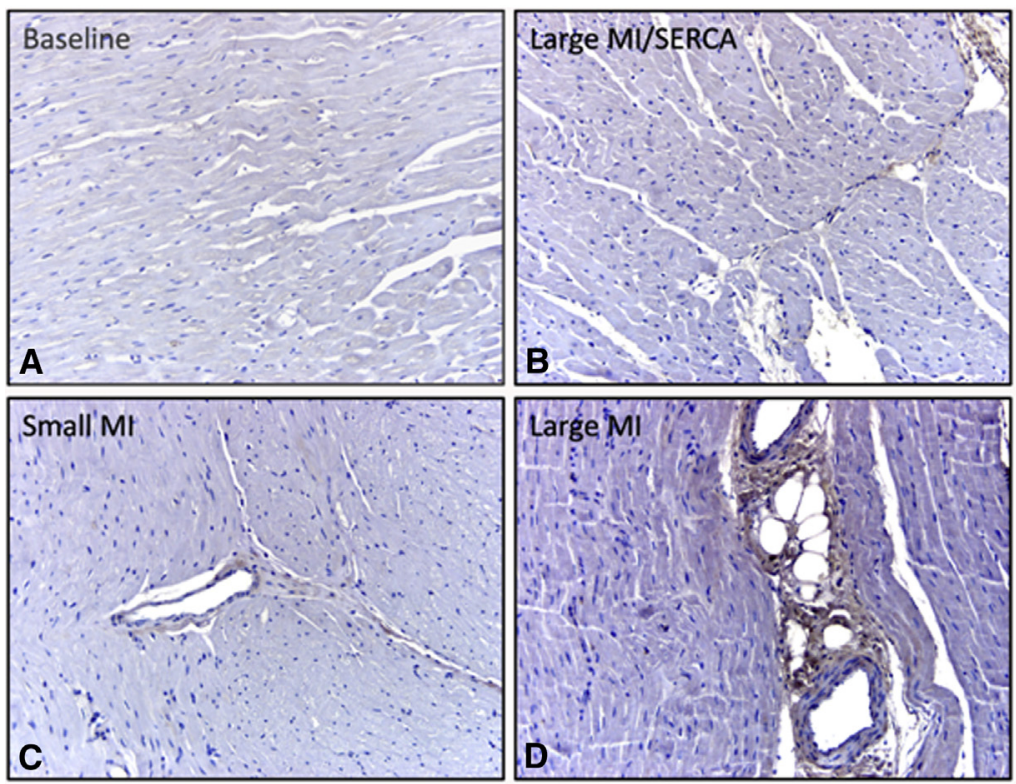

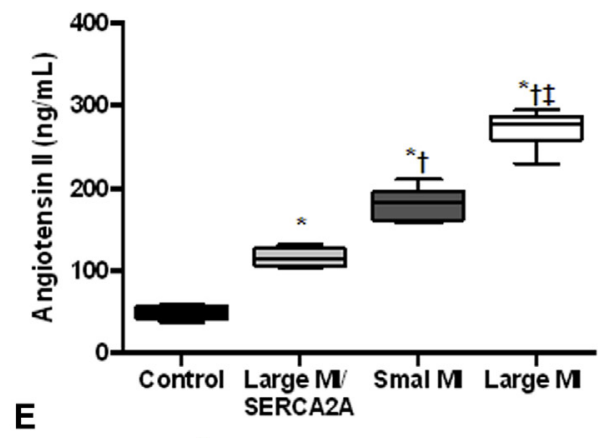

${ }^{*} p<0.05$ vs. Control $\dagger p<0.01$ vs. Large MI/SERCA $\ddagger \mathrm{p}<0.01$ vs. Small MI

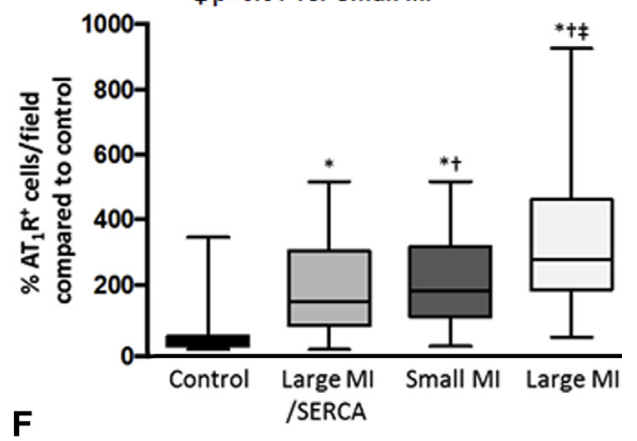

FIGURE E1. A-D, Immunohistochemical DAB staining (brown) for $\mathrm{AT}_{1} \mathrm{R}$ in myocardium of (A) control; (B) large MI/SERCA; (C) small MI; and (D) large MI groups. E, Angiotensin II plasma levels; (F) $\mathrm{AT}_{1} \mathrm{R}$ expression. Whisker-plot analysis shows total range of $\mathrm{AT}_{1} \mathrm{R}$ positive cells (determined by $\mathrm{DAB}$ immunohistochemistry) across all heart sections. The solid line in the middle represents the median; upper and lower crossbars encompass the middle 50th percentile. $M I$, Myocardial infarction; SERCA, sarcoplasmic reticulum calcium adenosine triphosphatase; $A T_{1} R$, angiotensin II receptor 1. 